\title{
GABA selectively increases mucin-1 expression in isolated pig jejunum
}

\author{
Hannah-Sophie Braun ${ }^{1} \cdot$ Gerhard Sponder $^{1} \cdot$ Robert Pieper $^{2} \cdot$ Jörg R. Aschenbach $^{1}$ • \\ Carolin Deiner ${ }^{1}$ (B)
}

Received: 5 June 2015/Accepted: 5 October 2015/Published online: 15 October 2015

(C) Springer-Verlag Berlin Heidelberg 2015

\begin{abstract}
The inhibitory neurotransmitter GABA ( $\gamma$ aminobutyric acid) is synthesized by glutamic acid decarboxylase, which is expressed in the central nervous system and in various other tissues including the intestine. Moreover, GABA can be ingested in vegetarian diets or produced by bacterial commensals in the gastrointestinal tract. As previous studies in lung have suggested a link between locally increased GABA availability and mucin 5AC production, the present study sought to test whether the presence or lack of GABA (and its precursor glutamine) has an effect on intestinal mucin expression. Porcine jejunum epithelial preparations were incubated with two different amounts of GABA or glutamine on the mucosal side for $4 \mathrm{~h}$, and changes in the relative gene expression of seven different mucins, enzymes involved in mucin shedding, GABA B receptor, enzymes involved in glutamine/GABA metabolism, glutathione peroxidase 2, and interleukin 10 were examined by quantitative PCR (TaqMan ${ }^{\circledR}$ assays). Protein expression of mucin-1 (MUC1) was analyzed by Western blot. On the RNA level, only MUC1 was significantly up-regulated by both GABA concentrations compared with the control. Glutamine-treated groups showed
\end{abstract}

Jörg R. Aschenbach and Carolin Deiner have contributed equally to this work.

Electronic supplementary material The online version of this article (doi:10.1007/s12263-015-0497-8) contains supplementary material, which is available to authorized users.

Carolin Deiner

carolin.deiner@fu-berlin.de

1 Institute of Veterinary Physiology, FU Berlin, Oertzenweg 19b, 14163 Berlin, Germany

2 Institute of Animal Nutrition, FU Berlin, Koenigin-Luise-Str. 49, 14195 Berlin, Germany the same trend. On the protein level, all treatment groups showed a significantly higher MUC1 expression than the control group. We conclude that GABA selectively increases the expression of MUC1, a cell surface mucin that prevents the adhesion of microorganisms, because of its size and negative charge, and therefore propose that the well-described positive effects of glutamine on enterocytes and intestinal integrity are partly attributable to effects of its metabolite GABA.

Keywords GABA - Glutamine - Glutamic acid decarboxylase $\cdot$ Mucin $\cdot$ Gut health

\section{Introduction}

The nonprotein amino acid $\gamma$-aminobutyric acid (GABA) acts as an inhibitory neurotransmitter exhibiting sedative, antiepileptic, anxiolytic, pain killing, hypertension lowering, and muscle relaxing properties (Rudolph et al. 1999). Accordingly, current GABA pharmacology comprises selective hypnotics, non-sedative anxiolytics, memory enhancers, and powerful analgesics acting predominantly on central GABA receptors. Providers of functional foods containing high concentrations of GABA (e.g., GABA tea, fermented brown rice, GABA-rich soy sauce, and dairy products) have jumped on this bandwagon and claim effects such as the reduction in anxiety, promotion of sleep, or action as natural tranquilizers (Cheng and Tsai 2009; Okada et al. 2000). However, reports of beneficial effects after the consumption of such foods need cautious interpretation. This is based on our current understanding that GABA acting in the central nervous system (CNS) is exclusively synthesized there (Kuriyama and Sze 1971), because the zwitterion GABA is considered to be poorly 
permeable across the blood-brain barrier (Goldberg 2010). Synthesis of GABA is accomplished in brain and other tissues (e.g., gastrointestinal tract) by the enzyme glutamic acid decarboxylase (GAD) by the decarboxylation of glutamate (see Fig. 1), which, in turn, can be generated by the enzyme glutaminase (GLS) through the desamination of glutamine (Pinkus and Windmueller 1977). Isoforms of GAD are widely distributed throughout the animal and plant kingdom, from cockroach (Baxter and Torralba 1975) to Lactobacillus (Ueno et al. 1997) and from Escherichia coli (Fonda 1972) to tomato (Akihiro et al. 2008) and barley (Inatomi and Slaughter 1975). Accordingly, GABA is a natural component of the free amino acid pool of all kinds of ingested plants and probiotic/commensal bacteria in the gastrointestinal tract. Furthermore, the intestinal wall of the host is also able to produce GABA ( $\mathrm{Li}$ et al. 2012; Wang et al. 2004).

Experiments with mice have revealed that the ingestion of Lactobacillus rhamnosus (JB-1) can modify the expression level of GABA B and A receptors in some areas of the brain leading to increased stress resistance and anxiolysis (Bravo et al. 2011). The channel of communication between the gut and the CNS is proposed to be the vagus nerve (Bravo et al. 2011, 2012). Unfortunately, the molecular signal or product of the probiotic strain responsible for the effect on the GABAergic system (i.e., was it GABA or something else?) and the underlying molecular mechanisms remained unidentified.

In the present study, we have sought to test whether a tangible positive effect of GABA on its first and foremost interaction partner, namely the gut epithelium, can be identified. The epithelium is responsible for the production of mucins which are an important element of the innate gut immune system and consist of secreted mucin

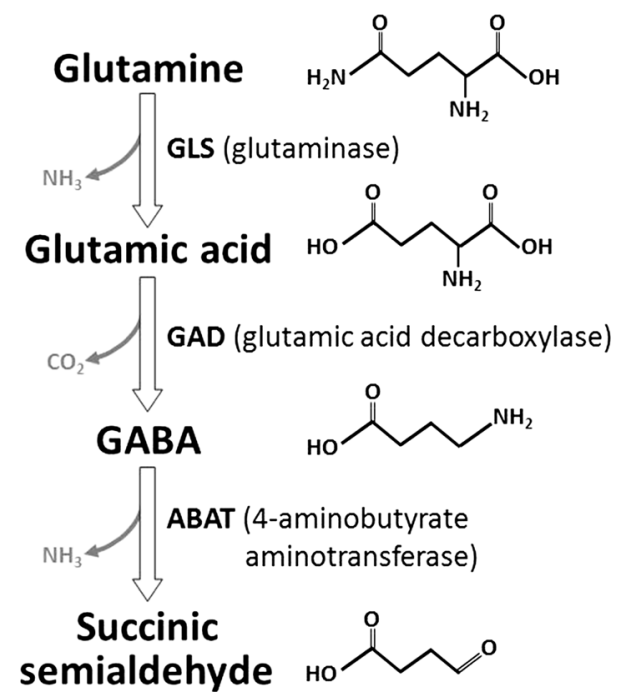

Fig. 1 Enzymes involved in the metabolism of GABA glycoproteins and attached mucins in the epithelium surface glycocalyx (McGuckin et al. 2011). Proceeding from previous results in airway epithelium of healthy smokers in whom a positive correlation had been described between mucin 5AC and GAD expression (Wang et al. 2010), we hypothesized a link between locally increased GABA availability and mucin production of the intestinal epithelium. To test this hypothesis, porcine jejunum was chosen as a model, because the small intestine is provided with the thinnest mucus layer (McGuckin et al. 2011) and should, therefore, benefit most from positive effects of GABA on mucus formation. Hence, we incubated isolated porcine jejunum epithelium with various concentrations of GABA and examined mucin expression, plus the expression of enzymes involved in mucin shedding, enzymes involved in GABA metabolism, anti-inflammatory interleukin 10 (IL10), and glutathione peroxidase 2 (GPx2). We further investigated whether the effects of GABA could be mimicked by application of its precursor glutamine. The latter amino acid is critical for several enterocyte functions and most of such glutamine effects have been linked to its metabolism by the intestine (Reeds and Burrin 2001). To select appropriate GABA concentrations for ex vivo experiments, we initially determined the natural GABA content in the digesta of different GI segments of slaughtered pigs. For comparison, the glutamine concentration of $1 \mathrm{mM}$ was chosen based on previous measurements of the physiological glutamine concentration in the jejunal lumen of weaned piglets (Wang et al. 2008).

\section{Materials and methods}

\section{GABA measurements in digesta}

To determine the normal GABA levels in the pig intestine, digesta samples of stomach, duodenum, mid jejunum, cecum, and mid colon of six pigs were taken immediately after slaughter at a local abattoir. The fluid phase of the digesta was extracted by centrifugation at $15,000 \mathrm{~g}$ for $15 \mathrm{~min}$ at $0{ }^{\circ} \mathrm{C}$, precipitated with $0.2 \mathrm{M}$ perchloric acid $1: 1$, and sent for HPLC analysis (Knauer GmbH, Berlin, Germany). Ultra-high-pressure liquid chromatography with electrospray ionization and mass spectrometry (UHPLCESI-MS) was performed by using 6-aminoquinolyl-N-hydroxysuccinimidyl carbamate (AQC) as a pre-column derivatization reagent (Cohen and Michaud 1993). Samples of the feed that pigs had received during the weeks before slaughter were homogenized in chromatography water (LiChrosolv, Merck Millipore, Darmstadt, Germany) at a ratio of $1 \mathrm{~g}: 3.5 \mathrm{ml}$ and processed accordingly (for feed composition see Supplementary Table 1). 


\section{Animals for ex vivo determination of GABA effects}

The protocol was approved by the local authorities (LAGeSo Berlin; T 0301/11). Three fattening pigs (one male, two female) at a weight of $28 \mathrm{~kg}$ were purchased from a local growth-finishing farm. Pigs were sedated by intramuscular injection of $25 \mathrm{mg}$ ketamine $\left(\right.$ Ursotamin $^{\circledR}$, Serumwerk Bernburg AG, Germany) and $4 \mathrm{mg}$ azaperone (Stresnil $^{\circledR}$, Janssen-Cilag, Neuss, Germany) per kg bodyweight and then killed by intracardial injection of $0.5 \mathrm{ml} /$ $\mathrm{kg} \mathrm{T} 61^{\circledR}$ (Intervet, Unterschleißheim, Germany). The jejunum was immediately removed from the abdominal cavity, rinsed, and stripped off from its outer muscle layers. The mucosal epithelium was placed in pre-warmed buffer solution (ingredients in mM: $105.0 \mathrm{NaCl}, 25.0 \mathrm{NaHCO}_{3}$, $0.96 \mathrm{KH}_{2} \mathrm{PO}_{4}, 2.0 \mathrm{~K}_{2} \mathrm{HPO}_{4}, 10.0$ glucose, 4.0 2-N-morpholinoethanesulfonic acid (MES), $1.5 \mathrm{CaCl}_{2}, 1.0 \mathrm{MgCl}_{2}$; $\mathrm{pH}$ 7.4), gassed with carbogen $\left(95 \% \mathrm{O}_{2}, 5 \% \mathrm{CO}_{2}\right)$, and taken to the laboratory.

\section{Ussing chamber setup}

From each pig, 15 pieces of epithelial preparations were mounted between the halves of conventional Ussing chambers (Martens et al. 1987) to allow for the separate incubation of the mucosal and the serosal sides and to be able to monitor tissue vitality during the experiment by measuring tissue conductance ( $G_{\mathrm{T}}$ value). The tissue was bathed on both sides with $16 \mathrm{ml}$ buffer solution (for composition, see previous section) at $38{ }^{\circ} \mathrm{C}$ and bubbled with carbogen. After a brief equilibration period (10 min after mounting), various amounts of a stock solution containing either $100 \mathrm{mM}$ GABA or $250 \mathrm{mM} \mathrm{L}$-glutamine were added on the mucosal side to obtain four treatment groups (with three epithelia per pig): $50 \mu \mathrm{M}$ GABA, $1.0 \mathrm{mM}$ GABA, $1.0 \mathrm{mM} \mathrm{L}$-glutamine, and $10.0 \mathrm{mM} \mathrm{L}-$ glutamine. Three chambers received no additive, and the tissue therein was incubated with buffer only to serve as a control group. To prevent osmotic effects, an osmotically equivalent amount of mannitol was added on the serosal side.

After $4 \mathrm{~h}$ of incubation, tissues were harvested, cut into pieces, and either snap-frozen in liquid nitrogen or fixed in RNAlater $^{\circledR}$ (Ambion/Life Technologies, Darmstadt, Germany) for protein or RNA isolation.

\section{Gene expression analysis}

Total RNA was isolated by using a commercial kit including a DNAse digestion step (Nucleospin RNA II, Macherey and Nagel, Dueren, Germany). RNA integrity numbers (RINs) were tested by using a lab-on-a-chip technique (RNA 6000 Nano Kit, Agilent, Waldbronn,
Germany). Only samples with RINs $>7.0$ were used for cDNA synthesis. Reverse transcription was performed with 500 ng RNA (750 ng for GAD) and an iScript ${ }^{\circledR}$ cDNA synthesis kit (Bio-Rad, Munich, Germany) according to the manufacturer's instructions, and reactions were diluted 1:10 (1:2 for GAD examination). Changes in the relative expression of mucins MUC1, MUC2, MUC3, MUC4, MUC12, MUC13, and MUC20, enzymes involved in glutamine/GABA metabolism (glutaminase, GLS; glutamic acid decarboxylase isoform 65 , GAD65; 4-aminobutyrate aminotransferase, ABAT), GABA B receptor subunit 1 (GBR1), enzymes involved in mucin shedding (a disintegrin and metalloprotease 17, ADAM17; matrix metallopeptidase 14, MMP14), GPx2, and IL10 were examined by quantitative reverse transcription polymerase chain reaction (qPCR) by means of TaqMan ${ }^{\circledR}$ assays (Applied Biosystems/Life Technologies, Darmstadt, Germany; $0.5 \mu \mathrm{l}$ per well) or gene-specific intron flanking primers and probes synthesized by Eurofins MWG Operon, Ebersberg, Germany (for assay IDs and sequences/concentrations, see Supplementary Tables 2 and 3). Isoform 67 of GAD (GAD67), MUC5AC, and GABA A receptor subunits $\beta_{2}, \beta_{3}$, and $\gamma_{2}$ were also tested but seemed not to be expressed in jejunum epithelium.

For qPCR experiments, a 40-cycle two-step PCR protocol $\left(20 \mathrm{~s}\right.$ at $60{ }^{\circ} \mathrm{C}$ and $1 \mathrm{~s}$ at $\left.95^{\circ} \mathrm{C}\right)$ was performed on a thermocycler (ViiA7, Applied Biosystems/Life Technologies) with $4.5 \mu \mathrm{l}$ cDNA and three replicates per reaction. TaqMan $^{\circledR}$ Fast Advanced Master Mix (Applied Biosystems/Life Technologies) or $\mathrm{iTaq}^{\circledR}$ Universal Probes Supermix (Bio-Rad) was used as mastermixes in assay volumes of $10 \mu \mathrm{l}$. Thresholds were automatically calculated by the cycler software. For data analysis, the software qbasePLUS (Biogazelle NV, Zwijnaarde, Belgium) was used to perform inter-run calibration, to determine dilution series-based gene-specific amplification efficiencies, and to test for expression stability of reference genes. Of the six reference genes tested, beta-2 microglobulin (B2 M) and beta-actin (ACTB) were recommended for the normalization of TaqMan runs, whereas glyceraldehyde 3-phosphate dehydrogenase (GAPDH) was suggested for runs with selfdesigned primers and probes. After the normalization of $\mathrm{Cq}$ values with the respective reference gene(s), results were scaled to the control group and exported as calibrated normalized relative quantity (CNRQ) values. Relative expression values were used for statistical analysis.

\section{Western blots}

Protein was isolated from $30 \mathrm{mg}$ frozen epithelium samples homogenized in $1 \mathrm{ml}$ extraction buffer containing $10 \mathrm{mM}$ Tris, $140 \mathrm{mM} \mathrm{NaCl}, 5 \mathrm{mM}$ EDTA, $1.0 \%$ Triton $\mathrm{X}-100,1.0 \mathrm{mM}$ phenylmethanesulfonyl fluoride, $1.0 \mathrm{mM}$ 
1,4-dithio-DL-threitol, and 3 tablets/200 $\mathrm{ml}$ complete EDTA-free Protease Inhibitor Cocktail Tablets (Roche Diagnostics, Mannheim, Germany). Total protein content was measured on a multimode plate reader $\left(\right.$ EnSpire ${ }^{\circledR}$, PerkinElmer, Rodgau, Germany) by using the Pierce ${ }^{\circledR}$ $660 \mathrm{~nm}$ Protein Assay (Thermo Scientific, Waltham, USA). Aliquots containing $200 \mu \mathrm{g}$ of protein were loaded per lane on a $10 \%$ Mini-PROTEAN TGX Stain-Free Precast Gel (Bio-Rad) containing a trihalo compound to induce a covalent reaction with tryptophan residues of the proteins in the gel when exposed to ultraviolet light. This enabled the blotting efficiency to be checked and allowed normalization in quantification analysis (Gilda and Gomes 2015; Gurtler et al. 2013). After semi-dry blotting, the polyvinylidene difluoride membrane (TransBlot Turbo Mini-size LF PVDF Membrane, Bio-Rad) was blocked with $5 \% \mathrm{w} / \mathrm{v}$ bovine serum albumin (BSA) in Tris-buffered saline + Tween $(50 \mathrm{mM}$ Tris, $150 \mathrm{mM} \mathrm{NaCl}$, $0.01 \%$ Tween-20, $\mathrm{pH}$ 7.6) for $2 \mathrm{~h}$, and then a rabbit polyclonal anti-mucin-1 antibody (ARP41446_T100, Aviva Systems Biology, San Diego, USA) was applied at a concentration of $2.5 \mu \mathrm{g} / \mathrm{ml}$ for $12 \mathrm{~h}$. A 1:1000 horseradish peroxidase (HRP)-linked goat anti-rabbit IgG (7074S, Cell Signaling Technology Inc., Danvers, USA) was used as a secondary antibody. The UV light-activated membrane was imaged by using the ChemiDoc MP Imaging system (Bio$\mathrm{Rad})$, and the relative amount of total protein in each lane on the blot was calculated by the software Image Lab 4.1 (Bio-Rad). The total protein signals were then used for the normalization of the specific signal, which was visualized with SuperSignal ${ }^{\circledR}$ West Dura Extended Duration Substrate (Thermo Scientific, Waltham, USA). Each specific band was normalized to the blackness of the respective lane by Image Lab 4.1 (Gilda and Gomes 2015), and results were given as normalized intensities (NI). Controls were always assumed as NI = 1 by the software. However, as only one sample could be defined as being the control, NI values of treated epithelia were related to each of the three control epithelia on the same blot and then averaged, finally resulting in nine relative values per treatment group.

\section{Statistical methods}

A one-way analysis of variance (ANOVA) test was performed by using the software Sigma Plot 11.0 (Systat Software GmbH, Erkrath, Germany). Data were tested for normality (Kolmogorov-Smirnov's test with Lilliefors correction) and equal variance (Levene's median test), and if either test failed, the Kruskal-Wallis one-way ANOVA on ranks was performed. Multiple comparisons (Dunnett's method) compared either the GABA- or the glutaminetreated groups with the control. $P$ values of $<0.05$ were considered to be statistically significant.

\section{Results}

\section{GABA measurements in digesta and pig feed}

In the digesta fluid of slaughtered pigs, the highest GABA concentrations were found in the stomach (median 27.6, min 4.8, max. $100.4 \mu \mathrm{mol} / \mathrm{l})$ and then decreased in the small intestine (duodenum median 4.9, $\min 3.4$, max 76.6; jejunum median 3.9, $\min 1.8, \max 26.2 \mu \mathrm{mol} / 1$; see Fig. 2). Toward the large bowel, GABA concentrations increased again (cecum median 16.5, min 12.2, $\max 22.8$; colon median 21.9. $\min 9.8, \max 53.2 \mu \mathrm{mol} / \mathrm{l})$. One-way ANOVA showed a difference between the segments $(P=0.047)$; this difference was attributable to significantly less GABA in the jejunum compared to the stomach and the colon, with intermediate values in the duodenum and cecum. GABA levels in three samples of the aqueous extract from pig feed were $179.8 \pm 11.4 \mu \mathrm{mol} / \mathrm{l}($ mean $\pm \mathrm{SD})$.

\section{Influence of GABA and glutamine application ex vivo on porcine jejunal epithelium}

Epithelia of all groups showed stable $G_{\mathrm{T}}$ values for the first $3 \mathrm{~h}$ of incubation with only slight increases toward the 4th hour, indicating good tissue vitality (data not shown).

\section{Gene expression analysis}

Relative expression data of MUC1 expression showed significant differences between both GABA concentrations and the control group (Fig. 3; Table 1). Both glutaminetreated groups also showed a trend for MUC1 mRNA up-

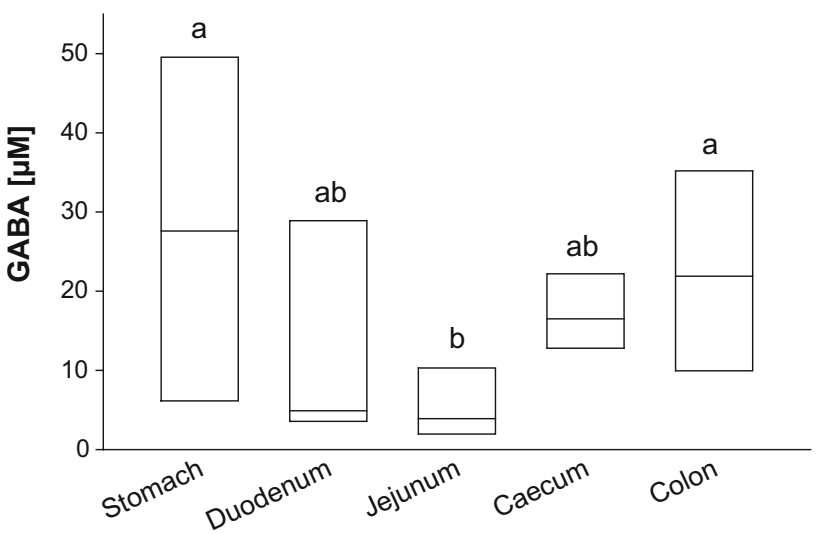

Fig. 2 GABA concentrations (medians and percentiles 25/75) in the digesta of various segments of the gastrointestinal tract. Digesta samples were taken immediately after slaughter, and GABA levels were determined by UHPLC-ESI-MS. $a, b$ Columns that do not share a common letter are significantly different $(P=0.036) ; n=6$. The GABA content in pig feed extract (produced from $1 \mathrm{~g}$ feed in $3.5 \mathrm{ml}$ ultrapure water) was $179.8 \mu \mathrm{M}$ 


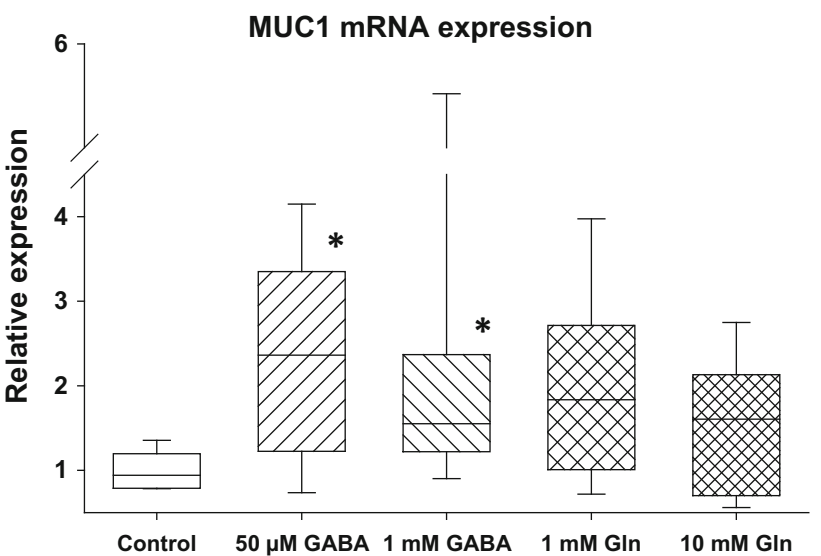

Fig. 3 Relative expression levels of mucin-1 mRNA in buffer control and in GABA- or glutamine-treated jejunum tissue samples. Original data were normalized to beta- 2 microglobulin and beta-actin and were calibrated to the mean of the control group. Box plots show 25/75 percentiles and medians. Asterisks indicate statistically significant differences between treatment and control $(P<0.05) . n=9$

regulation $(P=0.14)$. Other genes and mucins tested were not affected by the treatment (Table 1).

\section{Western blot}

As MUC1 gene expression was significantly affected by the treatment, MUC1 expression was verified on the protein level by Western blot (Fig. 4) and subsequent quantification (Fig. 5).
On the protein level, all treatment groups showed a significantly higher MUC1 expression than the control group $(P<0.05)$.

\section{Discussion}

The present study was initiated to test the hypothesis as to whether GABA is a novel signaling molecule for immune functions in the gastrointestinal tract. This hypothesis was derived from a finding in airway epithelium in which continuous irritating stimuli (smoking) induced an upregulation of the GABA-producing enzyme GAD67 coinciding with an increased production of MUC5AC (Wang et al. 2010). In the present study, we were able to show that dosages of luminal GABA in the upper range or exceeding the concentrations in porcine intestine induced a selective up-regulation of MUC1 at both the mRNA and protein levels. Thereby, we demonstrated, for the first time, a causal relationship between GABA and mucin production. With special reference to the intestine, this implies that GABA ingested with food or feed and GABA produced by the epithelium or indigenous bacteria in the gastrointestinal tract can have a direct and very specific stimulatory effect on a key component of the innate immune system. An analogy between the effects of GABA and glutamine further suggests that the endogenous synthesis of GABA upon glutamine exposure can likewise increase the resistance of

Table 1 Influence of mucosal incubation with GABA or glutamine on mRNA expression in porcine jejunum

\begin{tabular}{|c|c|c|c|c|c|c|c|c|c|c|}
\hline & MUC1 & \multicolumn{2}{|l|}{ MUC2 } & \multicolumn{2}{|l|}{ MUC3 } & \multicolumn{2}{|c|}{ MUC4 } & MUC12 & MUC13 & MUC20 \\
\hline Control & $1.00 \pm 0.07$ & \multicolumn{2}{|c|}{$1.00 \pm 0.11$} & \multicolumn{2}{|c|}{$1.00 \pm 0.16$} & \multicolumn{2}{|c|}{$1.00 \pm 0.24$} & $1.00 \pm 0.23$ & $1.00 \pm 0.24$ & $1.00 \pm 0.16$ \\
\hline $50 \mu \mathrm{M}$ GABA & $2.33 \pm 0.40$ & \multicolumn{2}{|c|}{$1.11 \pm 0.15$} & \multicolumn{2}{|c|}{$0.96 \pm 0.10$} & \multicolumn{2}{|c|}{$1.20 \pm 0.21$} & $0.56 \pm 0.10$ & $0.84 \pm 0.21$ & $0.88 \pm 0.17$ \\
\hline $1 \mathrm{mM}$ GABA & $2.04 \pm 0.50$ & \multicolumn{2}{|c|}{$1.29 \pm 0.09$} & \multicolumn{2}{|c|}{$0.92 \pm 0.11$} & \multicolumn{2}{|c|}{$0.90 \pm 0.20$} & $0.86 \pm 0.11$ & $0.95 \pm 0.20$ & $0.83 \pm 0.12$ \\
\hline$P$ value & 0.02 & \multicolumn{2}{|l|}{0.14} & \multicolumn{2}{|l|}{0.91} & \multicolumn{2}{|l|}{0.55} & 0.12 & 0.82 & 0.70 \\
\hline Control & $1.00 \pm 0.07$ & \multicolumn{2}{|c|}{$1.00 \pm 0.11$} & \multicolumn{2}{|c|}{$1.00 \pm 0.16$} & \multicolumn{2}{|c|}{$1.00 \pm 0.24$} & $1.00 \pm 0.23$ & $1.00 \pm 0.24$ & $1.00 \pm 0.16$ \\
\hline $1 \mathrm{mM}$ Gln & $1.99 \pm 0.36$ & \multicolumn{2}{|c|}{$1.07 \pm 0.06$} & \multicolumn{2}{|c|}{$0.98 \pm 0.12$} & \multicolumn{2}{|c|}{$1.00 \pm 0.21$} & $1.03 \pm 0.26$ & $0.96 \pm 0.18$ & $0.78 \pm 0.08$ \\
\hline $10 \mathrm{mM} \mathrm{Gln}$ & $1.47 \pm 0.26$ & \multicolumn{2}{|c|}{$0.93 \pm 0.10$} & \multicolumn{2}{|c|}{$1.27 \pm 0.25$} & \multicolumn{2}{|c|}{$0.71 \pm 0.15$} & $0.94 \pm 0.24$ & $0.71 \pm 0.15$ & $0.82 \pm 0.16$ \\
\hline \multirow[t]{2}{*}{$P$ value } & 0.14 & 0.55 & & 0.68 & & 0.35 & & 0.96 & 0.52 & 0.49 \\
\hline & GLS & GAD65 & & & GBR1 & & ADAM17 & MMP14 & GPx2 & IL10 \\
\hline Control & $1.00 \pm 0.24$ & $1.00 \pm 0.09$ & & \pm 0.29 & $1.00=$ & 0.11 & $1.00 \pm 0.18$ & $1.00 \pm 0.17$ & $1.00 \pm 0.19$ & $1.00 \pm 0.11$ \\
\hline $50 \mu \mathrm{M}$ GABA & $0.85 \pm 0.21$ & $1.48 \pm 0.30$ & & 0.15 & $1.00=$ & 0.07 & $0.86 \pm 0.24$ & $1.00 \pm 0.19$ & $1.00 \pm 0.14$ & $1.17 \pm 0.12$ \\
\hline $1 \mathrm{mM}$ GABA & $0.71 \pm 0.11$ & $1.14 \pm 0.21$ & & 0.11 & 1.02 & 08 & $0.78 \pm 0.15$ & $0.84 \pm 0.21$ & $0.87 \pm 0.16$ & $1.08 \pm 0.15$ \\
\hline$P$ value & 0.65 & 0.46 & 0. & & 0.62 & & 0.71 & 0.65 & 0.77 & 0.47 \\
\hline Control & $1.00 \pm 0.24$ & $1.00 \pm 0.09$ & & \pm 0.29 & $1.00=$ & 0.11 & $1.00 \pm 0.18$ & $1.00 \pm 0.17$ & $1.00 \pm 0.19$ & $1.00 \pm 0.11$ \\
\hline $1 \mathrm{mM}$ Gln & $0.70 \pm 0.08$ & $1.57 \pm 0.36$ & & \pm 0.08 & $1.01=$ & 0.08 & $0.68 \pm 0.11$ & $0.88 \pm 0.14$ & $1.03 \pm 0.20$ & $1.13 \pm 0.16$ \\
\hline $10 \mathrm{mM} \mathrm{Gln}$ & $1.01 \pm 0.34$ & $1.21 \pm 0.29$ & 0.8 & \pm 0.22 & $0.83=$ & 0.07 & $0.92 \pm 0.15$ & $1.15 \pm 0.18$ & $0.93 \pm 0.18$ & $1.13 \pm 0.12$ \\
\hline$P$ value & 0.77 & 0.80 & 0. & & 0.25 & & 0.30 & 0.54 & 0.95 & 0.68 \\
\hline
\end{tabular}

Data were normalized to beta-2 microglobulin and beta-actin (MUC1, MUC2, GAD65) or GAPDH (other genes) and scaled to the mean of the control group. Values represent mean \pm SEM. For abbreviations, see text section "Gene expression analysis"; $n=9$

Significant results are highlighted in bold 

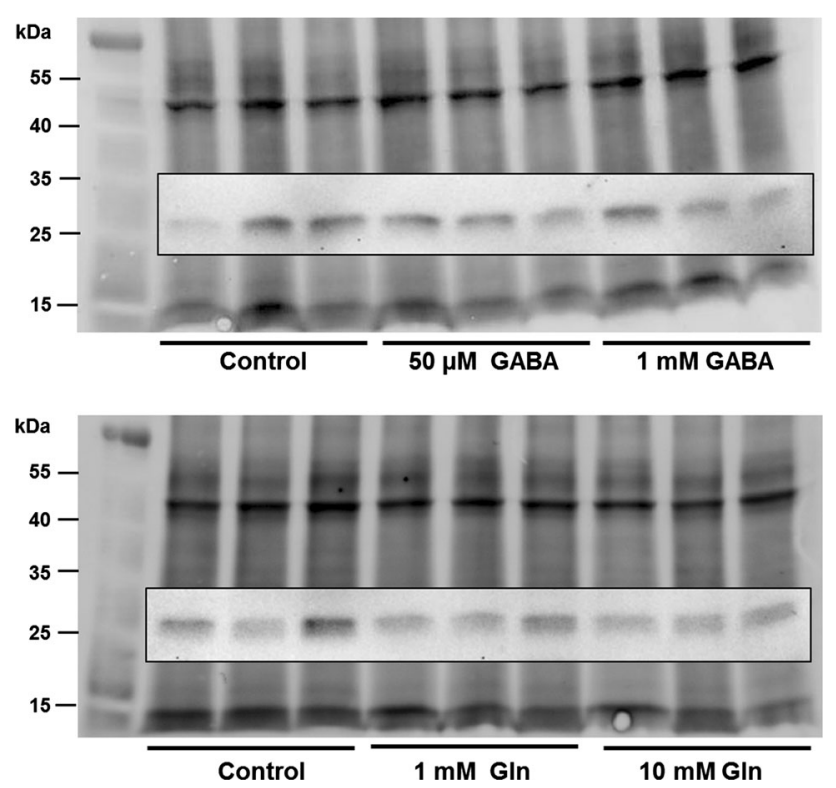

Fig. 4 Representative Western blots from one pig with three samples per group. Mucin-1 protein expression is presented in the small framed picture overlying the image taken for normalization (illustrating total protein load on the gel by UV-activated tryptophan residues): the intensity of each mucin-1-specific band was normalized (NI) to the blackness of its underlying total protein lane. Resulting NI values were compared to the control which was set to NI $=1$. MUC1 was up-regulated in all treatment groups receiving either GABA or glutamine (Gln) compared with the control tissues

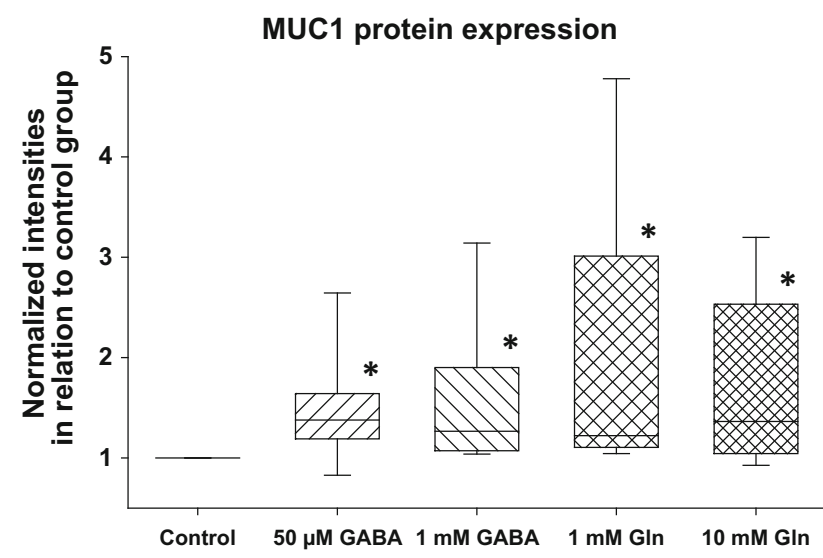

Fig. 5 Relative mucin-1 protein expression in the buffer control and in GABA- or glutamine (Gln)-treated jejunum samples. Original data were normalized to total protein and scaled to controls. Box plots show $25 / 75$ percentiles and medians. Asterisks indicate statistically significant differences between treatment and control $(P<0.05)$. $n=9$

the gut to infectious agents by up-regulating MUC1 expression.

The observation of McGuckin et al. (2011) that the mucus layer is at its thickest in the stomach and colon apparently not only correlates with the number and distribution of mucus-producing cells throughout the gastrointestinal tract but also with our finding that GABA levels are highest in the stomach and colon. The GABA in the stomach seems to be derived from the pig feed, which evidently contains high levels of GABA. The drop of luminal GABA concentration in the small intestine was anticipated based on the efficient GABA absorption observed in previous studies in Caco- 2 cells (Thwaites et al. 2000). The subsequent rise of luminal GABA toward the hindgut might be a result of water absorption in the large intestine, leading to a concentration of non-absorbed luminal GABA, but might also imply that new GABA is produced and released in the hindgut. The latter might occur as a result of the action of either the glutamic acid decarboxylases of gut microbiota or the endogenous GAD of the intestinal epithelium. Of these two options, bacteria as the major source are more likely, because endogenous GABA production is restricted to selected endocrine cells within the epithelium and to neurons that have been proposed to play a role in tissue maturation and differentiation (Gilon et al. 1987; Wang et al. 2006). Moreover, both commensal and potentially pathogenic bacteria are well known for their ability to synthesize and release large amounts of GABA, especially under acidic stress to remove cytoplasmic protons (Fonda 1972; Gorden and Small 1993; Hersh et al. 1996; Ueno et al. 1997). Under the assumption that bacterial metabolites influence the expression of mucus and its components, respectively, the observation that germfree rodents are provided with less cecal goblet cells and non-goblet mucous-type cells than conventionally raised/conventionalized rodents (Kandori et al. 1996; Ishikawa et al. 1989) becomes plausible.

The present study suggests that GABA incorporated with the food or produced inside the gut has significant local effects in the intestine, namely a selective up-regulation of MUC1. The MUC1 protein is the best characterized transmembrane mucin and is an important player of intestinal defense. For example, deficiency in MUC1 increases the susceptibility to infections by Campylobacter jejuni (McAuley et al. 2007) and Helicobacter pylori (McGuckin et al. 2007). MUC1 is translated as a single polypeptide that is then cleaved in the endoplasmic reticulum. The C-terminal domain anchors the protein to the cell surface and acts in signal transduction. In growth factor-triggered signaling pathways, this domain interacts with transcription factors, thereby driving the expression of genes involved in changes of the cytoskeleton and the adhesive capacity of the cell.

The extracellular domain of MUC1 has an extended structure with a large number of sialylated $O$-glycans. Chemically, sialic acids are nine-carbon monosaccharides and represent highly electronegative residues that influence the tertiary structure of proteins and protect them against proteolysis. In addition, they also act as binding partners for 
lectins. A surface lectin of macrophages has been shown to be able to bind MUC1 and to initiate signal transduction leading to cell growth and altered cell-cell adhesion (Tanida et al. 2013). Evidence has also been presented that a variety of lectins (not only lectins of immune cells) bind to mucins, e.g., wheat germ agglutinin (Jeffers et al. 2010) and parasite adherence lectin (Chadee et al. 1987). We can, therefore, assume that mucins generally bind lectins, including toxic/ harmful lectins from plants/legumes, fungi, bacteria, and viruses. Although doubts remain as to whether the binding of lectins always leads to signal transduction by MUC1, the detaining of alien molecules by binding them to carbohydrate moieties of the mucin layer is an important part of mucosal defense strategy.

The degree of sialylation and, hence, the resulting lectin binding capacity are regulated by enzymes including sialidases (i.e., neuraminidases) which are also found in bacteria (Gaskell et al. 1995). The pH optimum of bacterial sialidases is $\sim 5$ to 7 (Corfield et al. 1981), which would permit mucin desialylation by bacteria in the gut from the duodenum to colon. Desialylation by bacteria would facilitate the digestion of the mucin protein core and subsequent invasion of the epithelium. In such a scenario, GABA concentrations could serve the epithelium as an indirect measure for luminal bacterial loads. On the assumption that increasing bacterial loads increase the risk of MUC1 protein degradation and epithelial infection, an enhanced MUC1 expression by epithelial cells receiving the GABA signal could be valuable for initiating the replenishment of the protective mucus layer to compensate for mucolytic bacterial activity.

Having observed that GABA is a key signal for increasing MUC1 expression in isolated intestinal preparations, we further wished to determine whether the GABA precursor glutamine had a similar effect. Glutamine is a central amino acid in energy and nitrogen metabolism and constitutes the most abundant amino acid in the blood. It is an important fuel for enterocytes and stimulates protein synthesis (Higashiguchi et al. 1993). It is protective during intestinal inflammation [e.g., by the synthesis of heat shock protein 70 (Xue et al. 2011)] and supports healing in intestinal barrier dysfunction after severe trauma ( $\mathrm{Li}$ et al. 2002). During the weaning phase of piglets, dietary supplementation with $1 \%$ glutamine is able to prevent jejunal atrophy; this prevention is linked to enhanced growth performance (Wu et al. 1996). However, in cell culture, glutamine is also known to be of special importance as a nutritive factor. Deficiency in glutamine can even lead to apoptosis in cells that are under the influence of the oncogene MYC. Although the reasons are not clear, apoptosis is prevented when other substrates of the Krebs cycle (e.g., pyruvate, oxaloacetate) are available (Yuneva et al. 2007). This is in accordance with the general opinion that most glutamine effects are based on the delivery of substrates for ATP production in the Krebs cycle; for example, Yuneva et al. suggest that glutamine provides the Krebs cycle with a carbon chain and that this chain is the backbone of other intermediates. The present study suggests that metabolic conversion to GABA constitutes a second possibility by which glutamine can elicit beneficial effects on intestinal integrity.

Acknowledgments The authors Jörg R. Aschenbach and Carolin Deiner have received research grants from Pfizer Animal Health (now Zoetis).

\section{Compliance with ethical standards}

All institutional and national guidelines for the care and use of laboratory animals were followed.

Conflict of interest Hannah-Sophie Braun, Gerhard Sponder, Robert Pieper, Jörg R. Aschenbach, and Carolin Deiner declare that they have no conflict of interest.

\section{References}

Akihiro T, Koike S, Tani R, Tominaga T, Watanabe S, Iijima Y, Aoki K, Shibata D, Ashihara H, Matsukura C, Akama K, Fujimura T, Ezura H (2008) Biochemical mechanism on GABA accumulation during fruit development in tomato. Plant Cell Physiol 49:1378-1389. doi:10.1093/pcp/pcn113

Baxter CF, Torralba GF (1975) Gamma-aminobutyric acid and glutamate decarboxylase (1-glutamate 1-carboxy-lyase e.c. 4.1.1.15) in the nervous system of the cockroach, periplaneta americana.i.regional distribution and properties of the enzyme. Brain Res 84:383-397

Bravo JA, Forsythe P, Chew MV, Escaravage E, Savignac HM, Dinan TG, Bienenstock J, Cryan JF (2011) Ingestion of Lactobacillus strain regulates emotional behavior and central GABA receptor expression in a mouse via the vagus nerve. Proc Natl Acad Sci USA 108:16050-16055. doi:10.1073/pnas.1102999108

Bravo JA, Julio-Pieper M, Forsythe P, Kunze W, Dinan TG, Bienenstock J, Cryan JF (2012) Communication between gastrointestinal bacteria and the nervous system. Curr Opin Pharmacol 12:667-672. doi:10.1016/j.coph.2012.09.010

Chadee K, Petri WA Jr, Innes DJ, Ravdin JI (1987) Rat and human colonic mucins bind to and inhibit adherence lectin of Entamoeba histolytica. J Clin Invest 80:1245-1254. doi:10.1172/JCI113199

Cheng TC, Tsai JF (2009) GABA tea helps sleep. J Altern Complement Med 15:697-698. doi:10.1089/acm.2009.0023

Cohen SA, Michaud DP (1993) Synthesis of a fluorescent derivatizing reagent, 6-aminoquinolyl-N-hydroxysuccinimidyl carbamate, and its application for the analysis of hydrolysate amino acids via high-performance liquid chromatography. Anal Biochem 211:279-287. doi:10.1006/abio.1993.1270

Corfield AP, Veh RW, Wember M, Michalski JC, Schauer R (1981) The release of N-acetyl- and N-glycolloyl-neuraminic acid from soluble complex carbohydrates and erythrocytes by bacterial, viral and mammalian sialidases. Biochem J 197:293-299

Fonda ML (1972) Glutamate decarboxylase. Substrate specificity and inhibition by carboxylic acids. Biochemistry 11:1304-1309

Gaskell A, Crennell S, Taylor G (1995) The three domains of a bacterial sialidase: a beta-propeller, an immunoglobulin module and a galactose-binding jelly-roll. Structure 3:1197-1205 
Gilda JE, Gomes AV (2015) Western blotting using in-gel protein labeling as a normalization control: stain-free technology. Methods Mol Biol 1295:381-391. doi:10.1007/978-1-49392550-6_27

Gilon P, Reusens-Billen B, Remacle C, Janssens de Varebeke P, Pauwels G, Hoet JJ (1987) Localization of high-affinity GABA uptake and GABA content in the rat duodenum during development. Cell Tissue Res 249:593-600

Goldberg JS (2010) Selected gamma aminobutyric acid (GABA) esters may provide analgesia for some central pain conditions. Perspect Medicin Chem 4:23-31. doi:10.4137/PMC.S5490

Gorden J, Small PL (1993) Acid resistance in enteric bacteria. Infect Immun 61:364-367

Gurtler A, Kunz N, Gomolka M, Hornhardt S, Friedl AA, McDonald K, Kohn JE, Posch A (2013) Stain-free technology as a normalization tool in Western blot analysis. Anal Biochem 433:105-111. doi:10.1016/j.ab.2012.10.010

Hersh BM, Farooq FT, Barstad DN, Blankenhorn DL, Slonczewski JL (1996) A glutamate-dependent acid resistance gene in Escherichia coli. J Bacteriol 178:3978-3981

Higashiguchi T, Hasselgren PO, Wagner K, Fischer JE (1993) Effect of glutamine on protein synthesis in isolated intestinal epithelial cells. JPEN-Parenter Enter 17:307-314

Inatomi K, Slaughter JC (1975) Glutamate decarboxylase from barley embryos and roots. General properties and the occurrence of three enzymic forms. Biochem J 147:479-484

Ishikawa K, Satoh Y, Oomori Y, Yamano M, Matsuda M, Ono K (1989) Influence of conventionalization on cecal wall structure of germ-free Wistar rats: quantitative light and qualitative electron microscopic observations. Anat Embryol (Berl) 180:191-198

Jeffers F, Fuell C, Tailford LE, Mackenzie DA, Bongaerts RJ, Juge N (2010) Mucin-lectin interactions assessed by flow cytometry. Carbohyd Res 345:1486-1491. doi:10.1016/j.carres.2010.05.012

Kandori H, Hirayama K, Takeda M, Doi K (1996) Histochemical, lectin-histochemical and morphometrical characteristics of intestinal goblet cells of germfree and conventional mice. Exp Anim 45:155-160

Kuriyama K, Sze PY (1971) Blood-brain barrier to H3-gammaaminobutyric acid in normal and amino oxyacetic acid-treated animals. Neuropharmacology 10:103-108

Li JY, Lu Y, Hu S, Sun D, Yao YM (2002) Preventive effect of glutamine on intestinal barrier dysfunction induced by severe trauma. World J Gastroenterol 8:168-171

Li Y, Xiang YY, Lu WY, Liu C, Li J (2012) A novel role of intestine epithelial GABAergic signaling in regulating intestinal fluid secretion. Am J Physiol-Gastr Liver Physiol 303:G453-G460. doi:10.1152/ajpgi.00497.2011

Martens H, Gabel G, Strozyk H (1987) The effect of potassium and the transmural potential difference on magnesium transport across an isolated preparation of sheep rumen epithelium. Q J Exp Physiol 72:181-188

McAuley JL, Linden SK, Png CW, King RM, Pennington HL, Gendler SJ, Florin TH, Hill GR, Korolik V, McGuckin MA (2007) MUC1 cell surface mucin is a critical element of the mucosal barrier to infection. J Clin Invest 117:2313-2324. doi:10.1172/JCI26705

McGuckin MA, Every AL, Skene CD, Linden SK, Chionh YT, Swierczak A, McAuley J, Harbour S, Kaparakis M, Ferrero R, Sutton P (2007) Muc1 mucin limits both Helicobacter pylori colonization of the murine gastric mucosa and associated gastritis. Gastroenterology 133:1210-1218. doi:10.1053/j.gas tro.2007.07.003
McGuckin MA, Linden SK, Sutton P, Florin TH (2011) Mucin dynamics and enteric pathogens. Nat Rev Microbiol 9:265-278. doi:10.1038/nrmicro2538

Okada T, Sugishita T, Murakami T, Murai H, Saikusa T, Horino T, Onoda A, Kajimoto O, Takahashi R, Takahashi T (2000) Effect of the defatted rice germ enriched with GABA for sleeplessness, depression, autonomic disorder by oral administration. J Jpn Soc Food Sci 47:8. doi:10.3136/nskkk.47.596

Pinkus LM, Windmueller HG (1977) Phosphate-dependent glutaminase of small intestine: localization and role in intestinal glutamine metabolism. Arch Biochem Biophys 182:506-517. doi:10.1016/0003-9861(77)90531-8

Reeds PJ, Burrin DG (2001) Glutamine and the bowel. J Nutr 131:2505S-2508S (discussion 2523S-2504S)

Rudolph U, Crestani F, Benke D, Brunig I, Benson JA, Fritschy JM, Martin JR, Bluethmann H, Mohler H (1999) Benzodiazepine actions mediated by specific gamma-aminobutyric acid(A) receptor subtypes. Nature 401:796-800. doi:10.1038/44579

Tanida S, Akita K, Ishida A, Mori Y, Toda M, Inoue M, Ohta M, Yashiro M, Sawada T, Hirakawa K, Nakada H (2013) Binding of the sialic acid-binding lectin, Siglec-9, to the membrane mucin, MUC1, induces recruitment of beta-catenin and subsequent cell growth. J Biol Chem 288:31842-31852. doi:10.1074/jbc.M113. 471318

Thwaites DT, Basterfield L, McCleave PM, Carter SM, Simmons NL (2000) Gamma-Aminobutyric acid (GABA) transport across human intestinal epithelial $(\mathrm{Caco}-2)$ cell monolayers. $\mathrm{Br} \mathrm{J}$ Pharmacol 129:457-464. doi:10.1038/sj.bjp.0703069

Ueno Y, Hayakawa K, Takahashi S, Oda K (1997) Purification and characterization of glutamate decarboxylase from Lactobacillus brevis IFO 12005. Biosci Biotech Biochem 61:1168-1171. doi:10.1271/bbb.61.1168

Wang FY, Watanabe M, Zhu RM, Maemura K (2004) Characteristic expression of gamma-aminobutyric acid and glutamate decarboxylase in rat jejunum and its relation to differentiation of epithelial cells. World J Gastroenterol 10:3608-3611

Wang FY, Zhu RM, Maemura K, Hirata I, Katsu K, Watanabe M (2006) Expression of gamma-aminobutyric acid and glutamic acid decarboxylases in rat descending colon and their relation to epithelial differentiation. Chin J Dig Dis 7:103-108. doi:10. 1111/j.1443-9573.2006.00247.x

Wang J, Chen L, Li P, Li X, Zhou H, Wang F, Li D, Yin Y, Wu G (2008) Gene expression is altered in piglet small intestine by weaning and dietary glutamine supplementation. J Nutr 138:1025-1032

Wang G, Wang R, Ferris B, Salit J, Strulovici-Barel Y, Hackett NR, Crystal RG (2010) Smoking-mediated up-regulation of GAD67 expression in the human airway epithelium. Respir Res 11:150. doi:10.1186/1465-9921-11-150

Wu G, Meier SA, Knabe DA (1996) Dietary glutamine supplementation prevents jejunal atrophy in weaned pigs. J Nutr 126:2578-2584

Xue H, Sufit AJ, Wischmeyer PE (2011) Glutamine therapy improves outcome of in vitro and in vivo experimental colitis models. JPENParenter Enter 35:188-197. doi:10.1177/0148607110381407

Yuneva M, Zamboni N, Oefner P, Sachidanandam R, Lazebnik Y (2007) Deficiency in glutamine but not glucose induces MYCdependent apoptosis in human cells. J Cell Biol 178:93-105. doi: $10.1083 /$ jcb.200703099 